\title{
A Three-Parameter S-Shaped Function of Flood Return Period and Damage
}

\author{
Chaochao Li, ${ }^{1,2}$ Xiaotao Cheng, ${ }^{1} \mathrm{Na} \mathrm{Li}^{1}{ }^{1} \mathrm{Zhongmin} \mathrm{Liang,}^{2}$ Yanyan Wang, ${ }^{1}$ and Song Han \\ ${ }^{1}$ State Key Laboratory of Simulation and Regulation of Water Cycle in River Basin, Research Center on Flood \& Drought Disaster \\ Reduction of the Ministry of Water Resources, China Institute of Water Resources and Hydropower Research, Beijing 100038, China \\ ${ }^{2}$ College of Water Conservancy and Hydropower Engineering, Hohai University, Nanjing 210098, China
}

Correspondence should be addressed to Chaochao Li; lcc0828@gmail.com

Received 23 December 2015; Revised 19 April 2016; Accepted 19 May 2016

Academic Editor: Huan Wu

Copyright (C) 2016 Chaochao Li et al. This is an open access article distributed under the Creative Commons Attribution License, which permits unrestricted use, distribution, and reproduction in any medium, provided the original work is properly cited.

\begin{abstract}
With growing flood risk due to increased urbanization, flood damage assessment and flood risk management must be reconsidered. To demonstrate and assess the new features and trends of flood risk in urbanized areas, a novel S-shaped function of return period and damage $(R-D)$ is proposed. The function contains three parameters, which are defined as the maximum flood damage $A$, critical return period $R_{c}$, and integrated loss coefficient $k$. A basic framework for flood damage assessment was established to evaluate flood damage in the Taihu Basin under various scenarios. The simulation results were used to construct the flood $R-D$ functions. The study results show that the flood $R-D$ model based on the Gompertz function agrees well with the mutability of flood damage in the highly urbanized basin when the flood scale exceeds the defense capability. The $R-D$ function can be utilized for timely and effective flood damage assessment and prediction. It can describe the impacts of socioeconomic development, urbanization degree, and flood control capability improvements well. The turning points of the function curve can be used as gradation criteria for rational strategy development associated with flood hazards.
\end{abstract}

\section{Introduction}

In modern society, with increasing population density and assets in flood control districts, under equivalent scales of flooding, flood damage is higher than it was in the past. To ensure security, a comprehensive system of flood control mechanisms has been built, and the flood control standard has been improved continuously. Disaster mitigation benefits can be achieved by optionally adopting flood control mechanisms. However, for events with extreme peak flows beyond design standards, the associated flood damage sharply increases $[1,2]$. It is important to determine the evolutionary trends of flood risk in modern society. The formation mechanisms of chain reactions and mutability of floods provide the basis for predictive controls [3]. The relationship between flood return period and flood damage should be constructed based on a comprehensive consideration of the impacts of economic development, urbanization degree, and flood control capacity changes. Reasonable gradation criteria associated with flood hazards provide crucial information for strategy development and planning adaptation.

According to the Atlas of Mortality and Economic Losses from Weather, Climate and Water Extremes 1970-2012, storms and floods accounted for nearly 80 percent of all disasters due to weather, climate, and water extremes, resulting in nearly half of the related mortalities and over 80 percent of economic losses. As the population and wealth increase in urban areas, the flood risk also increases. Konrad reported that urbanization resulted in 2-year, 10-year, and 100-year flood peak increases by $100 \% \sim 600 \%, 20 \% \sim 300 \%$, and $10 \% \sim 250 \%$, respectively [4]. Current assessments of flood damage mainly focus on direct economic loss. There are three main methods of flood damage assessment: (1) the traditional investigation method, (2) assessment models based on mathematical methods, and (3) integrated models based on geographic information system and remote sensing (GIS/RS). Investigation is the most basic method. The data integrity demand is high for this method. In the traditional investigation method, researchers 
complete field investigations of property loss and casualties after disasters occur. It requires considerable manpower and is not suitable for predicting flood damage. Field survey and investigation data provide a foundation for flood damage assessment. Damage assessment models based on mathematical methods have been widely used. They can be divided into two types. One calculates flood damage by constructing flood loss rates for hazard-affected bodies. This type of model sets the water depth or submerged period as an independent variable and flood loss rate as a dependent variable. Then, regression equations of water depth or submerged period and flood loss rate are established [5]. For example, PenningRowsell and Chatterton [6] and Parker et al. [7] proposed 140 flood vulnerability curves. HAZUS-MH includes more than 900 damage curves for estimating damage to various types of buildings and infrastructures $[8,9]$. Australia and Japan built vulnerability curves for damage estimation of different buildings [10]. The other type includes rapid assessment methods, such as fuzzy comprehensive evaluations, grey correlation analyses, genetic algorithms, and BP neural networks [11-16]. These methods require reliable historical flood data. China currently lacks a historical flood database. In addition, the reliability of socioeconomic and property loss data is poor. With the technological development of hydrologic models, hydraulic models, RS, and GIS, integrated models have been widely used in recent years. Flood inundation information is the input data used in these methods. Then, inundation information and socioeconomic information are analyzed by spatial overlay $[17,18]$. Detailed geographic data are needed to construct integrated models based on GIS/RS. Therefore, mathematical methods and integrated models based on GIS/RS are combined to construct $R-D$ function curves, which are established for rapid and effective flood damage assessment.

S-shaped growth curves are often utilized to describe variable growth processes such as slow growth, fast growth, and decay. Because hazard-affected bodies have defensive and recoverable capabilities, the flood damage development process will be bounded. In the initial phase, flood damage increases slowly because of resistance effects. Due to increasing flood or rainfall accumulation, the energy exceeds the defensive capability. Then, a rapid development phase occurs. Finally, with an energy release, the development process enters the attenuation phase. In previous studies, Li et al. found that the general type of damage loss mimics an Sshaped curve $[19,20]$. Yu et al. developed direct economic loss curves for the minimum, maximum, and most likely floods based on a Monte Carlo method [21]. These loss curves are all $\mathrm{S}$-shaped. Hence, it is reasonable to build S-shaped functional curves of flood damage.

Some studies have attempted to build damage functions by curve fitting. For example, Chen et al. established a water-induced disaster damage curve based on a hyperbolic tangent function [22]. However, the meanings of parameters in the S-shaped function were not defined according to their physical meanings. Additionally, the function curve cannot describe the impacts of socioeconomic development, urbanization, and flood control capability changes. Including flood protection mechanisms and urbanization in $R-D$ functions is novel and can indicate resilience changes. In this paper, mathematical methods and integrated models based on GIS were combined to construct $R-D$ function curves. They can be utilized for flood damage assessment and prediction. The chain reaction associated with a flood disaster was analyzed, and the mutability feature of flood damage was summarized. The Taihu Basin in China was taken as the study area. Several S-shaped functions were selected to construct the $R-D$ functions, which can be used for rational strategy development.

\section{Methods and Materials}

2.1. The Study Area. The Taihu Basin, which is located in the estuary areas of the Yangtze and Qiantang Rivers, is one of the most important economic regions in China (Figure 1). The Taihu Basin has developed rapidly due to its various advantages, such as high agricultural production, a developed industry, a stable economic base, and a dense population. Because the basin is a phialiform region with a lower center and surrounding highlands, it is prone to serious flood disasters caused by plum rains, typhoons, and storm surges. Features of flood risk in the Taihu Basin are very sensitive to both climate changes and rapid urbanization [25]. The influence of urbanization is discussed in this paper.

Urbanized areas in the Taihu Basin increased by over four times from 1995 to 2010 . Meanwhile, the cultivated area decreased by nearly 40 percent, and the population increased by 3.65 million in the past 10 years (Figure 2). The most serious flood disasters in the Taihu Basin occurred in 1954, 1991, and 1999. Since then, various flood control mechanisms have been built, such as dikes, sluices, polders, and pump stations. The evolutionary trends and key features of flood risk have changed in the urbanized basin. The main factors are rainfall, urbanization, and socioeconomic and flood control mechanisms.

2.2. Procedure. The flood risk assessment framework is adopted in this paper from the China/UK scientific cooperation project "China-UK Scenario Analysis Technology for River Basin Flood Risk Management in the Taihu Basin" [26]. The methodology contains a number of steps (Figure 3).

(1) Hydrological Data Collection and Frequency Analysis. The analysis results are used as inputs for hydraulic modelling and $R-D$ modelling.

(2) Climate Input Analysis. The hydrological system is simulated using the distributed hydrological models. A variable infiltration capacity (VIC) model is used to model fluvial inflows, and the Soil Conservation Service Curve Number (SCS CN) method is applied to determine direct rainfall inputs [27].

(3) Broad-Scale Hydraulic Analysis. A hydrodynamic model (ISIS) is used to model the movements of water through the network of channels and flood storage cells in the basin [28].

(4) Economic Prediction. Future climate scenarios are generated using the Providing Regional Climates for Impacts 


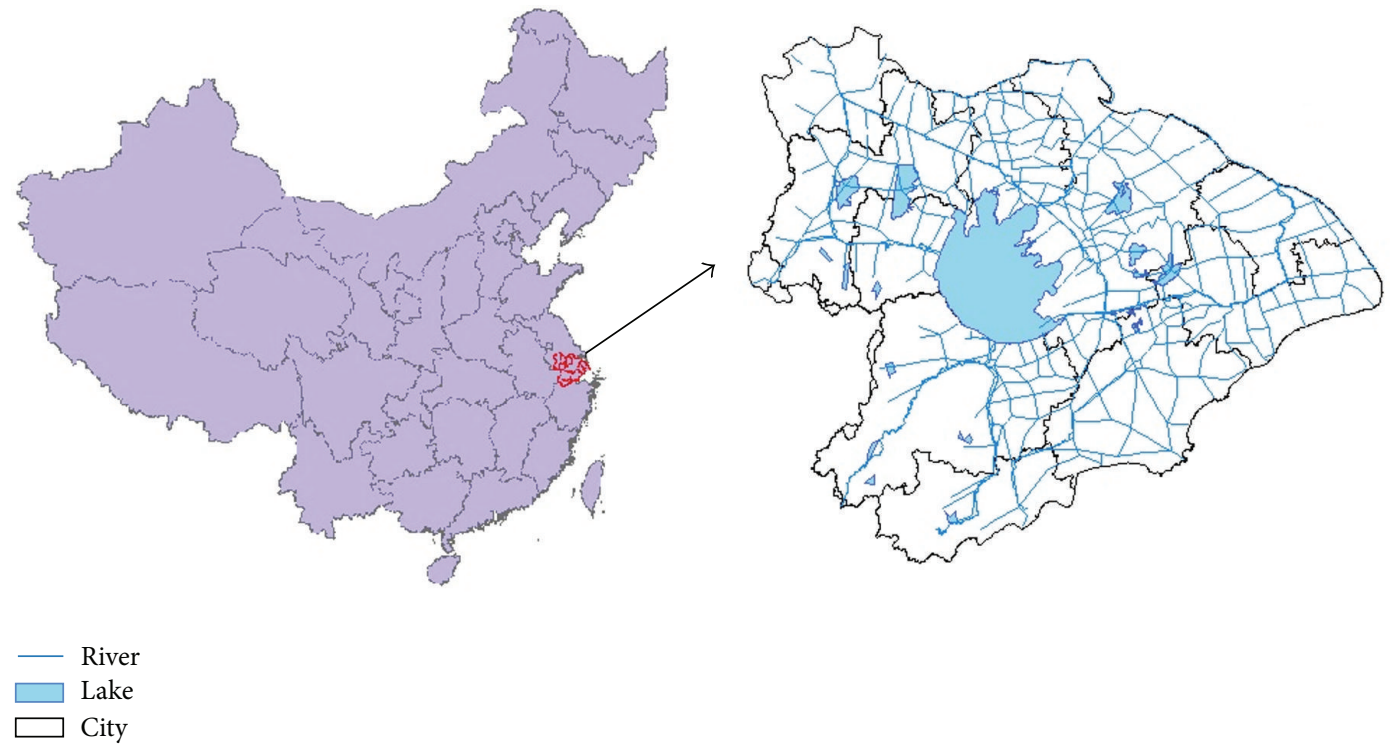

Figure 1: The location of the Taihu Basin.

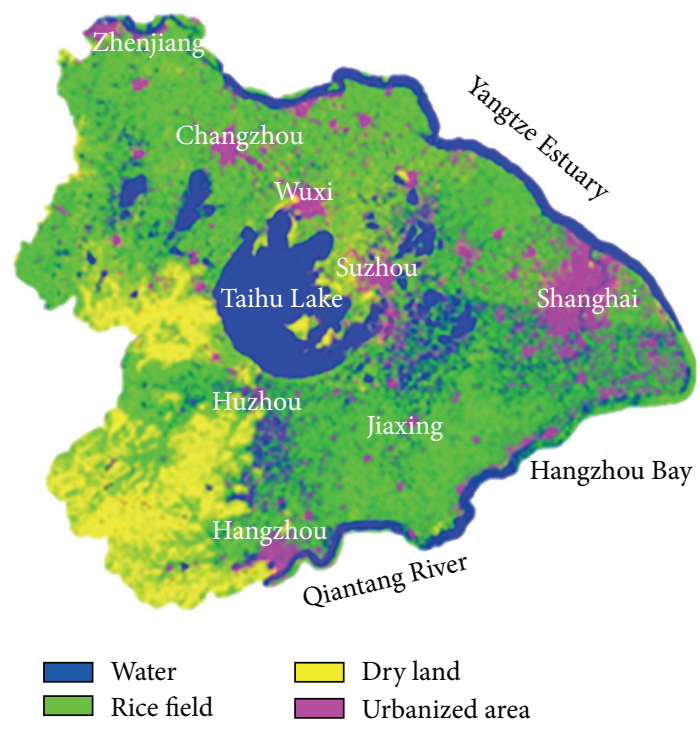

(a) Land use in 2000/2001

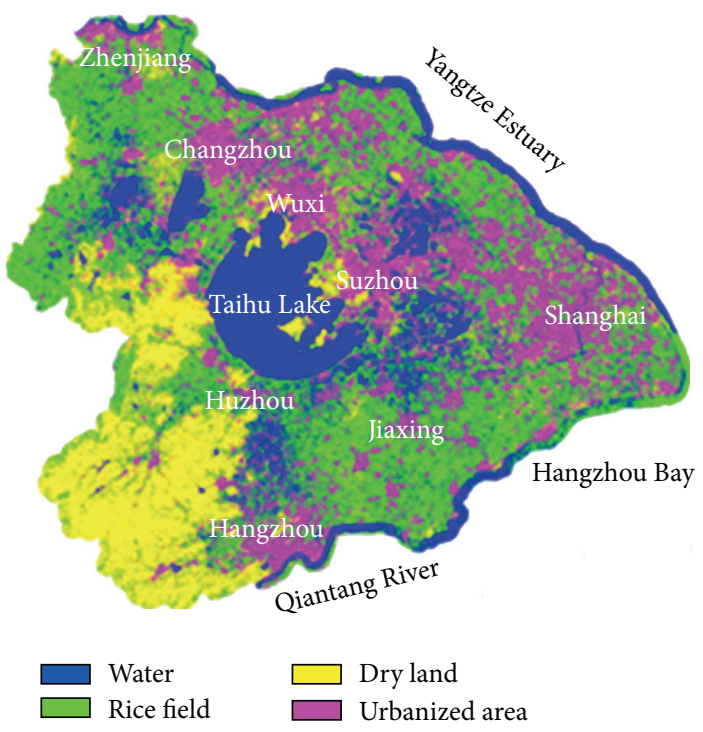

(b) Land use in 2009/2010

FIGURE 2: Changes in land use types from 2000 to 2010 in the Taihu Basin [23].

Studies (PRECIS) regional climate model. The downscaling method is used to predict economic factors. Details can be found in Penning-Rowsell et al. [29]. The economic index is predicted based on the population, economy, agricultural land, economic structure, urbanization rate, family properties, and so forth.

(5) Flood Damage Assessments. The Taihu Basin Risk Assessment System (TBRAS) risk analysis model is established to model inundation depths in the flood cells and calculate associated economic damage [30].
(6) Flood Damage Function Construction. The simulation results of flood damage assessment modelling are taken as samples to construct the flood $R-D$ functions.

2.3. Data. Data were acquired from the China/UK scientific cooperation project. The 30 -day design rainfalls with frequencies of $0.001,0.002,0.005,0.01,0.02$, and 0.05 were used as flood hazard data. Socioeconomic and land use changes are considered in the future scenario. Societal development is established based on the statistical downscaling method 


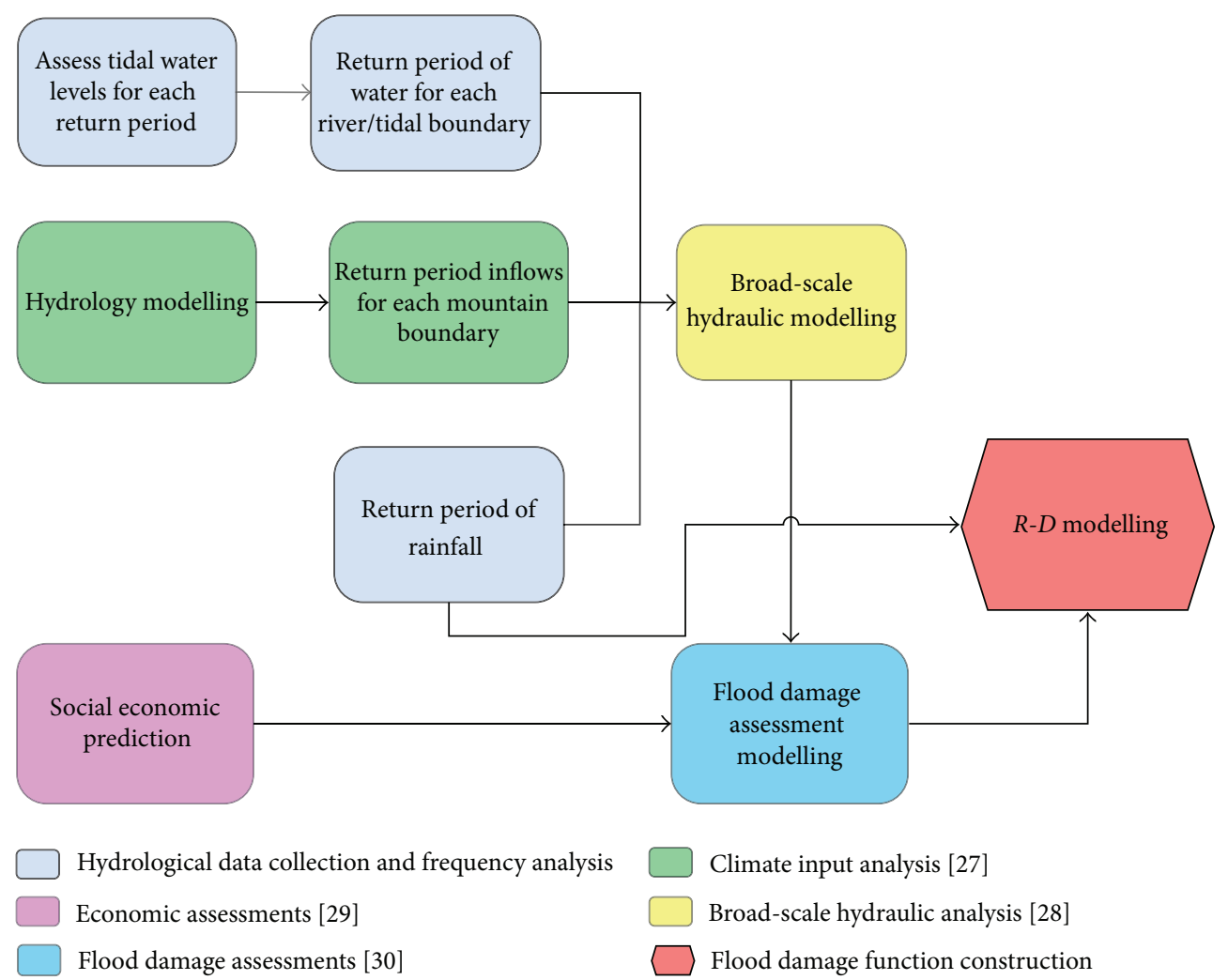

Figure 3: Basic framework of flood risk analysis [24].

according to the IPCC A2 emission scenario. The development of the world is uneven, and regional characteristics are enhanced. The economy develops at a medium speed. The population continues to grow. However, the agricultural land use pattern shows a rapid decline. The current data and predicted population and GDP results are shown in Table 1.

The hydrological model, hydrodynamic model, and flood loss assessment model were validated. The most serious flood disasters in the Taihu Basin occurred in 1991 and 1999. The surveyed flood damage cases were 141 million CNY in 1999. The scale of Taihu Basin flood in 1999 is over 100 years. According to studies by Liu et al. [27] and Wicks et al. [28], the hydrology-hydraulics model was evaluated against observations from 1999. The simulation results of flood damage are shown in Table 2. The simulated 100-year and 200-year flood damage cases in 1999 were 104 million and 176 million, respectively. The simulation value and survey value are of the same order of magnitude. With the consideration of uneven distributions of rainfall in time and space, the assessment of the flood return period may not be entirely consistent with the actual situation. However, the damage assessment results are reliable and can be utilized as samples for $R-D$ function construction.

2.4. Characterizing Urbanized Area Floods. With basin urbanization, the flood risk shows new characteristics. In rural areas, the main economic losses associated with flood disasters are agricultural losses, and the affected area is equal to the inundated area. However, in urban areas, the economic
TABLE 1: Predicted results of GDP and population.

\begin{tabular}{|c|c|c|c|c|c|}
\hline & 1999 & 2005 & 2020 A2 & 2030 A2 & 2050 A2 \\
\hline $\begin{array}{l}\text { GDP (100 } \\
\text { million CNY) }\end{array}$ & 10768 & 20216 & 38946 & 62008 & 108131 \\
\hline $\begin{array}{l}\text { Population } \\
\text { (million) }\end{array}$ & 44.71 & 47.14 & 54.07 & 58.87 & 68.46 \\
\hline
\end{tabular}

TABLE 2: Simulation results of flood damage (unit: 100 million CNY).

\begin{tabular}{lccccc}
\hline $\begin{array}{l}\text { Return } \\
\text { period } \\
\text { (years) }\end{array}$ & $\begin{array}{c}\text { Flood } \\
\text { frequency }\end{array}$ & 1999 & 2005 & $2030 \mathrm{~A} 2$ & $2050 \mathrm{~A} 2$ \\
\hline 1000 & 0.001 & 312.0 & 457.3 & 1003.5 & 1556.3 \\
500 & 0.002 & 291.0 & 427 & 939.09 & 1455.5 \\
200 & 0.005 & 176.0 & 259.1 & 575.8 & 904.7 \\
100 & 0.01 & 104.0 & 161.7 & 365.5 & 578 \\
50 & 0.02 & 65.0 & 85.4 & 239.3 & 381.7 \\
20 & 0.05 & 35.0 & 56.2 & 129.3 & 206.8 \\
10 & 0.1 & 12.0 & 21.8 & 52.9 & 86.9 \\
2 & 0.5 & 0.55 & 0.90 & 1.8 & 2.87 \\
\hline
\end{tabular}

losses are much higher, and the affected area is much larger than the inundated area. The indirect economic loss is even more than the direct economic loss. To reduce the flood risk in modern society effectively, the formation mechanisms 
of flood-induced chain reactions and mutability must be researched intensively.

2.4.1. Chain Reaction of an Urban Flood Disaster. The chain reaction associated with a flood disaster is a series of lifeline system damage cases or failures that occur at the same time or in succession. After the key systems suffer damage due to flooding, the chain reaction forms, and the flood damage expands sharply. Lifeline systems include types of infrastructures that maintain normal operation in modern cities, such as traffic, communication, internet, water supply, power supply, gas supply, waste disposal, sewage treatment, and drainage systems. For example, during the "Beijing 21 July" urban storm event in 2012, some drainage pumps stopped running due to power system damage, and the waterlogged roads led to traffic gridlock. The most vulnerable systems can be identified and better protected through chain reaction analyses. Power supply systems may be the most vulnerable systems, and key facilities must be moved from low-lying areas to higher elevations or protected by special measures according to the risk analysis. Meanwhile, key link nodes can be found and cut off to stop further extension of the flood damage. After the drainage pump stations stop working due to power outages, the anticipatory standby generators or circuits for pumping stations can be started promptly to ensure normal operation of drainage systems during storm events. Flood chain reactions include both positive and negative feedback between floods and lifeline systems. Making full use of the negative feedback, we can minimize costs to obtain larger benefits of flood prevention. Furthermore, city landscapes and sports venues can be designed as parts of the flood regulation system with temporary rain storage functions.

2.4.2. Mutability of Urban Flood Damage. The mutability of flood damage is a phenomenon that occurs when the flood damage suddenly increases near a certain frequency or return period of a flood. In Beijing, the direct economic loss associated with flood disasters from 2006 to 2008 was about 20 million CNY. The flood disaster loss of the " 23 June 2011" rainstorm was 13.83 billion CNY. The flood disaster loss of the " 21 July 2012" rainstorm surged to 162.15 billion CNY. The maximum point rainfall in Beijing city was $460 \mathrm{~mm}$ (nearly a 500-year rainfall event), and the mean areal rainfall was $170 \mathrm{~mm}$. The maximum point rainfall in the urban center was $328 \mathrm{~mm}$ (nearly a 100-year rainfall event), and the mean areal rainfall was $215 \mathrm{~mm}$. The main rivers in Beijing are "protected" by 50 -year to 100 -year levees. According to the data, the flood disaster loss increased sharply in 2012, which proves the existence of mutability of urban flood damage. Within the flood control capacity, flood risk can be reduced effectively and the flood alleviation benefits are significant. After the flood magnitude exceeds the flood control standard, the loss will sharply increase and exhibit features of mutability. It is difficult to meet the increasing demand for flood control solely based on structural measures. Appropriate nonstructural measures provide sound strategies for sustainable development. Through studying the mutability phenomenon, the critical flood frequency or return period can be determined and used to classify the disaster grades.

\subsection{The Construction of Flood Damage Functions}

2.5.1. The Definition of Flood Risk Functions and Parameters. In recent years, a widely accepted concept in flood risk studies has been termed expected annual damage (EAD) [31-33]. It can be expressed as follows:

$$
\text { Risk }=\int_{0}^{1} D(p) d p,
$$

where $D$ is the damage of a given flood event and $p$ is the probability of this flood event within a year.

The return period $R$ is used instead of probability $p$ and $p=1 / R$. The risk can then be expressed as follows:

$$
\text { Risk }=\int_{0}^{\infty} D(R) d R .
$$

$D(R)$ can be expressed as an S-shaped function according to the analysis above. $R$ is an independent variable, and $D$ is a dependent variable. A typical S-shaped function has three parameters. These parameters should describe the chain reaction and mutability features in an urbanized basin. The following assumptions are made. (1) The maximum value of flood damage $A$ is associated with the socioeconomic indexes. (2) The abscissa of the inflection point is defined as the critical return period $R_{c}$, which is associated with the integrated flood control standard. (3) The slope of the function curve can be adjusted by the integrated loss coefficient $k$, which is associated with the flood vulnerability indexes.

2.5.2. The Determination Methods of Parameters. As shown in Figure 4, the flood $R-D$ function curve is S-shaped. The characteristics of the $D(R)$ function are summarized as follows. (1) $D(R)$ monotonically increases. (2) The curve contains two key points: $\mathrm{A}$ and $\mathrm{B}$. Point $\mathrm{A}$ is called the damage-arising point, and a rainfall event can lead to flood damage after point A. Point B is called the damage-ceasing point, when flood damage gradually approaches an extremum value. (3) Point $\mathrm{C}$ is the inflexion point, at which the rate of change in damage begins to decline. It is also called the damage transition point. These three points divide the $D_{2}(R)$ curve into four parts that can be used to determine standard grades of flood disaster damage. The four grades are small, medium, large, and larger.

Their corresponding values can be determined using function derivatives. Line $d D(R) / d R$ and line $d D^{2}(R) / d R^{2}$ are the first and second derivative curves of $D(R)$, respectively (Figure 5). The first derivative function indicates that the slope of the flood damage curve is highest when $R=R_{c}$. Point $A$ and point $B$ are the extreme points based on the slope change of curve, that is, the extreme points of the second derivative of the $D(R)$ function.

The maximum value of flood damage $A$, critical return period $R_{c}$, and integrated loss coefficient $k$ are the three main parameters, which can be determined through experience, experimental simulations, or curve fitting. Historical data or simulation data can be utilized for curve fitting. Mathematical statistical analysis tools can be used to determine the values of the parameters and draw diagrams of $R-D$ function curves. 


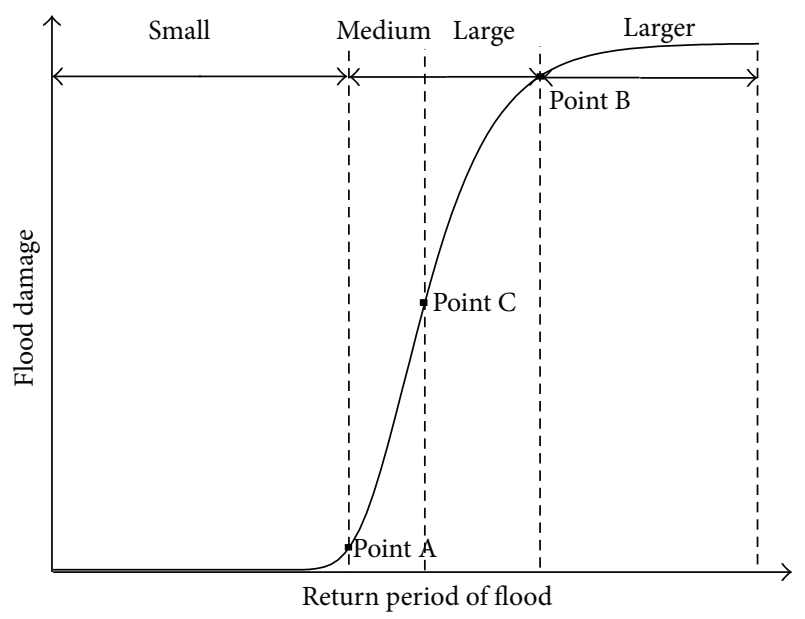

Figure 4: Flood R-D function curve.

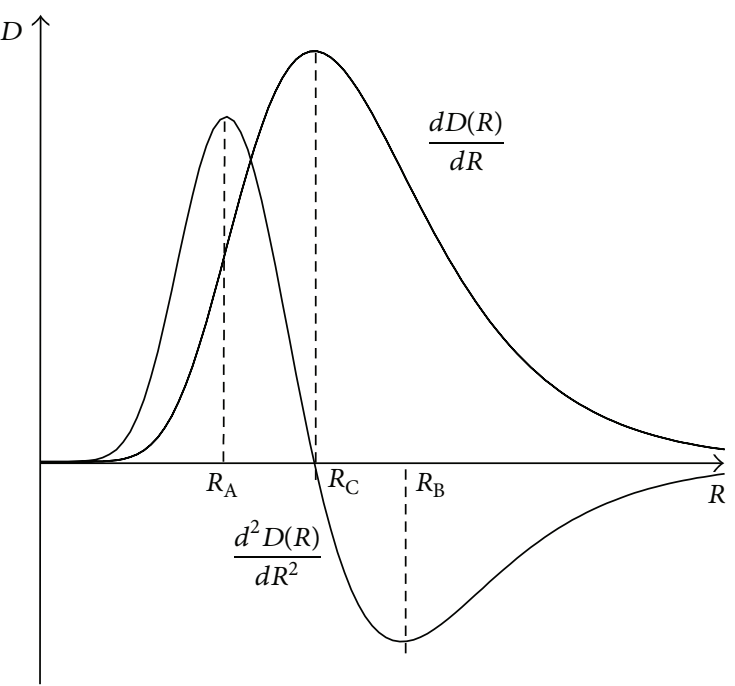

Figure 5: The first and second derivative curves of an $R-D$ function.

Some commonly used tools include Origin, SPSS (Statistical Product and Service Solutions), and the MATLAB Curve Fitting Toolbox.

2.6. Conceptual Model. According to the chain reaction and mutability analysis of urban flood, $R-D$ function variations are caused by socioeconomic, flood control capability, and flood vulnerability changes. Hence, four scenarios are assumed according to the impact factors.

Scenario 1 (undeveloped basin). The relationship between flood or rainfall return period and flood damage in an undeveloped state is illustrated by the black line. With increases in water depth and inundated area, the flood damage increases.

Scenario 2 (developed basin). Due to socioeconomic growth, the flood damage in a developed basin is larger than that in an undeveloped basin. The $R-D$ function curve shifts upward.

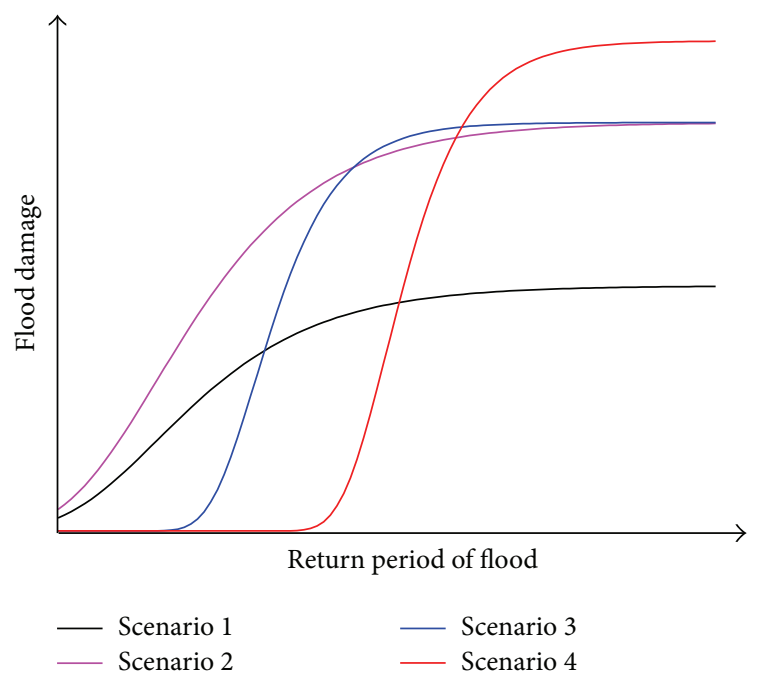

Figure 6: Conceptual $R-D$ function curves.

Scenario 3 (protected basin). To prevent flood disasters, a flood control system is built. Within the flood control standard, the flood damage decreases significantly. The slope of the curve reaches a maximum value when the return period of the flood is near the flood control standard.

Scenario 4 (further developed and protected basin). With further improvement of the flood control standard and socioeconomic factors, the $R-D$ function curve will shift to the upper right, as demonstrated by the red line in Figure 6.

2.7. Function Selection. In practice, some commonly used S-shaped curves are summed, such as the logistic curve, Gompertz curve, and Richards curve. According to the conceptual analysis of the flood $R-D$ function, three $S$-shaped functions with three parameters were selected. The functions are the Gompertz function, logistics function, and hyperbolic tangent function.

(1) Gompertz Function. Consider

$$
D=A e^{-e^{-k\left(R-R_{c}\right)}} .
$$

In (3), $D$ is the flood damage, $R$ is the return period of the flood, $A$ is the maximum damage, $R_{c}$ is the critical period, and $k$ is the integrated loss coefficient. The function characteristics are as follows: the minimum value is zero, the maximum value is $A$, the abscissa of the critical point is $R_{c}$, and the maximum slope is $A k / e$.

(2) Logistics Function. Consider

$$
D=\frac{A}{1+e^{-k\left(R-R_{c}\right)}}
$$

The function characteristics are as follows: the minimum value is zero, the maximum value is $A$, the abscissa of the critical point is $R_{c}$, and the maximum slope is $A k / e$. 
TABLE 3: Function fitting results in 1999.

\begin{tabular}{lcccc}
\hline Function & Parameter & Value & $\begin{array}{c}\text { Standard } \\
\text { error }\end{array}$ & $\begin{array}{c}\text { Adj. } \\
R \text {-squared }\end{array}$ \\
\hline Gompertz & $A$ (100 million) & 306.08 & 11.86 & \\
& $R_{c}$ (year) & 120.53 & 11.33 & 0.99 \\
Logistics & $k$ & 0.0088 & 0.0011 & \\
& $A(100$ million) & 301.30 & 14.86 & \\
\hline \multirow{2}{*}{ Hyperbolic } & $A(100$ million) & 301.31 & 14.86 & \\
tangent & $R_{c}$ (year) & 166.62 & 16.93 & 0.97 \\
& $k$ & 0.0074 & 0.0013 & \\
\hline
\end{tabular}

TABLE 4: Function fitting results in 2005.

\begin{tabular}{lcccc}
\hline Function & Parameter & Value & $\begin{array}{c}\text { Standard } \\
\text { error }\end{array}$ & $\begin{array}{c}\text { Adj. } \\
\text {-squared }\end{array}$ \\
\hline Gompertz & $A$ (100 million) & 448.20 & 17.19 & \\
& $R_{c}$ (year) & 118.46 & 11.076 & 0.99 \\
\hline \multirow{4}{*}{ Logistics } & $k$ & 0.0088 & 0.0011 & \\
& $A$ (100 million) & 441.53 & 21.90 & \\
\hline \multirow{2}{*}{ Hyperbolic } & $A(100$ million) & 441.56 & 21.90 & \\
tangent & $R_{c}$ (year) & 164.58 & 16.91 & 0.97 \\
& $k$ & 0.0074 & 0.0013 & \\
\hline
\end{tabular}

(3) Hyperbolic Tangent Function. Consider

$$
D=\frac{A}{2}\left(\frac{e^{2 k\left(R-R_{c}\right)}-1}{e^{2 k\left(R-R_{c}\right)}+1}+1\right) .
$$

The function characteristics are as follows: the minimum value is zero, the maximum value is $A$, the abscissa of the critical point is $R_{c}$, and the maximum slope is $A k / 2$.

\section{Results and Discussion}

3.1. Results of Status Scenarios. Data from 1999 and 2005 were used as a basic sample, and the fitting results of three functions are shown in Tables 3 and 4 . The parameter values and standard errors of the logistics and hyperbolic tangent functions are almost the same. The maximum flood damage $A$ values in 1999 and 2005 were 301 and 442 billion CNY, respectively. The standard errors of $A$ in 1999 and 2005 were 14.86 and 21.90, respectively. The average critical return period is approximately 165.61 years. The ordinate of the inflection point is $A / 2$, and the growth process is symmetrical. However, there is no such characteristic in the Gompertz function. The maximum flood damage $A$ values are 306 and 448 billion, the standard errors of $A$ are 11.86 and 17.19 , and the average critical return period is approximately 120 years. The maximum flood damage $A$ is larger, but its standard error is smaller than others, and the maximum flood damage $A$ is much closer to the flood damage of a 1000 -year

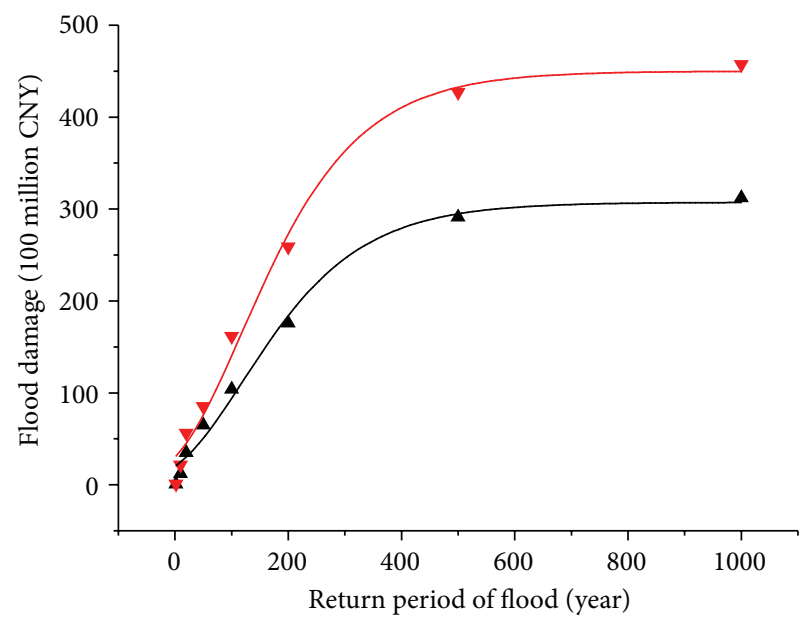

$\begin{array}{ll}\text { - Sample of } 1999 & - \text { Gompertz fit of } 1999 \\ \text { v Sample of } 2005 & - \text { Gompertz fit of } 2005\end{array}$

FIGURE 7: Gompertz function fitting results in 1999 and 2005.

flood. The adjusted $R^{2}$ is particularly useful in the feature selection stage of model building. The closer this value is to one, the better the model fit is. The Gompertz function best reflects flood damage compared to the estimates of the other functions. Therefore, the Gompertz function is selected for future scenario fitting. The fitting results of the Gompertz function are shown in Figure 7.

The most serious flood disasters in the Taihu Basin occurred in 1991 and 1999. The surveyed flood damage cases were 113 and 141 million. The maximum $30 \mathrm{~d}$ rainfall in 1991 was $502 \mathrm{~mm}$, which is nearly equivalent to an 80 -year return period flood. The average areal rainfall in 1999 over various characteristic periods $(7 \mathrm{~d}, 30 \mathrm{~d}, 60 \mathrm{~d}$, and $90 \mathrm{~d}$ ) was close to or over the 100-year level [34]. The $R-D$ curve of the Taihu Basin in 1999 is shown in Figure 7. The 100-year and 200year flood damage cases in 1999 simulated by the $R-D$ curve are 112 million and 183 million, respectively. The simulated and surveyed values of flood damage are of the same order of magnitude. Due to uneven distributions of rainfall in time and space, the estimated rainfall return periods are very different. The flood $R-D$ curve is reliable for damage assessment.

3.2. Results of Future Scenarios. The Gompertz function is chosen for flood damage prediction. According to the fitting results of the Gompertz function, the mean value of the critical return period $R_{c}$ is 119.5 years, and the result is rounded up to 120 years. The mean value of the integrated loss rate $k$ is 0.0088 . The linear relationship between GDP and flood damage is established based on a 1000-year return period. The values of maximum flood damage $A$ are shown in Table 5. The Gompertz function fitting result of future scenarios is shown in Figure 8. The curve fitting results and example data match well. The flood $R-D$ models of 2030 and 2050 based on the Gompertz function exhibit good agreement with the mutability of flood damage in highly 


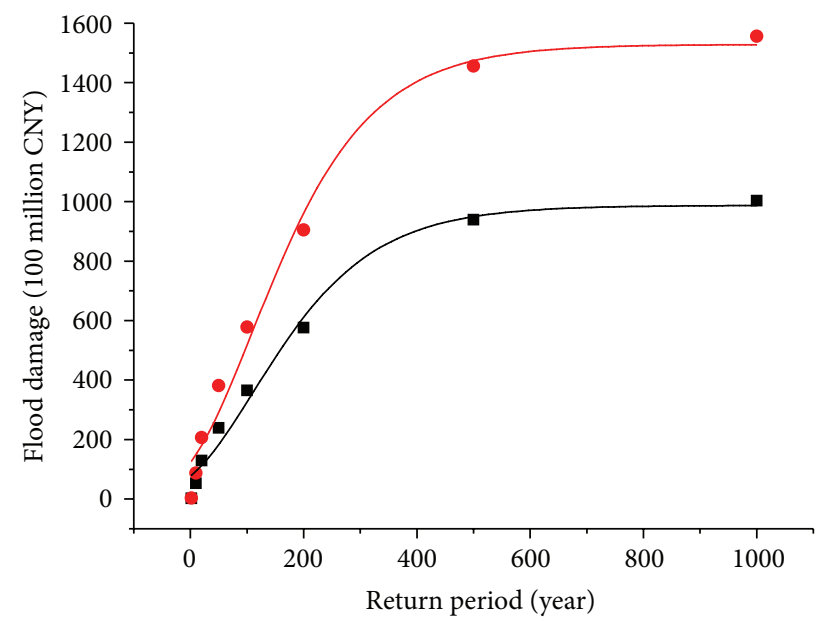

- Sample of 2030 A2 - Gompertz fit of 2030 A2

- Sample of 2050 A2 - Gompertz fit of 2050 A2

FIGURE 8: Gompertz function fitting results in 2030 and 2050.

TABLE 5: The values of the maximum flood damage $A$ (100 million).

\begin{tabular}{lcccc}
\hline Year & 1999 & 2005 & $2030 \mathrm{~A} 2$ & $2050 \mathrm{~A} 2$ \\
\hline$A$ & 306 & 448 & 980 & 1566 \\
\hline
\end{tabular}

urbanized basins when the scale of a flood exceeds the defense capability.

3.3. Discussion. The most serious flood disasters in the Taihu Basin occurred in 1954, 1991, and 1999. These flood events were mainly caused by plum rains. According to the statistical data associated with plum rains in Taihu basin from 1954 to 2009 , the average onset and end dates of plum rains are 15 June and 8 July, respectively. Thus, 30 days is chosen as the characteristic period in this study. With the extension of the characteristic period, the total rainfall increases. Thus, the flood damage also increases. If the characteristic period increases (e.g., $3 \mathrm{~d}, 7 \mathrm{~d}, 60 \mathrm{~d}$, or $90 \mathrm{~d}$ ), the function curve will shift upward; however, the overall shape of the function will not change. In the Taihu Basin, the characteristic period of 30 days approximates the average period of the plum rain season. It is suitable for flood damage assessment in largescale basins.

The evolutionary trends of flood risk in urbanized basins change. Flood damage assessments should describe the impacts of socioeconomic development, urbanization, and flood control capability improvements. $R-D$ function curves are used as effective evaluation methods for flood damage assessment and prediction. Compared with mathematical evaluation methods, $R-D$ functions do not require many historical flood disaster data. The data used to construct $R-D$ functions are the simulation results of flood damage assessment models based on GIS. Flood $R-D$ functions can convert these discrete points into continuity equations. Assessment and prediction of flood damage for any flood

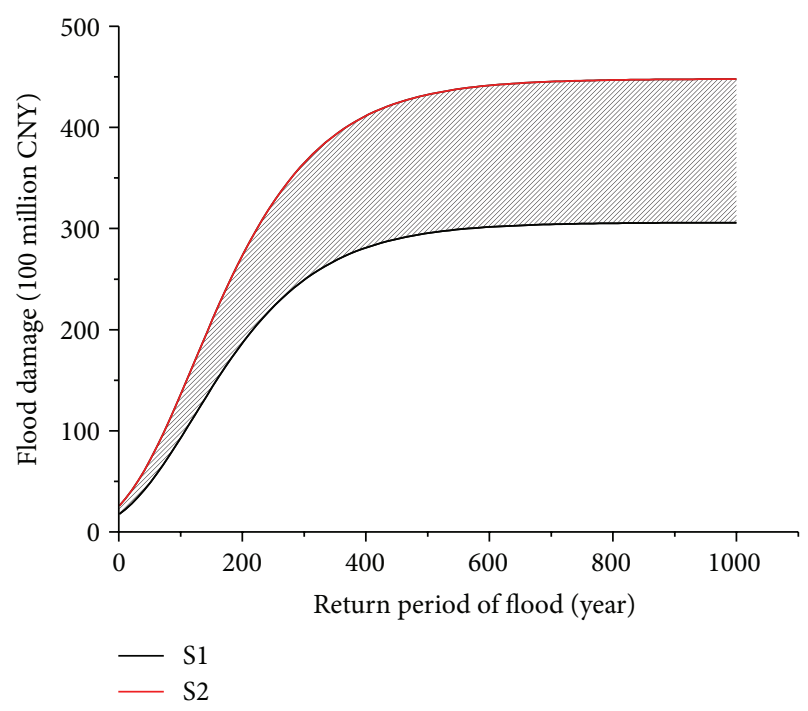

Figure 9: The impact of economic development.

return period can be quickly acquired by consulting figures. The applicability is more extended than those in previous studies. It can be utilized to estimate urbanization impacts and alleviation benefits.

3.3.1. The Evolutionary Trends of Future Flood Risk. According to the results of future scenarios, $R-D$ functions can demonstrate the evolutionary tendencies of flood risk due to economic growth. The maximum flood damage $A$ is related to GDP. The flood damage function curve in 1999 is taken as inherent characteristic curve $\mathrm{S} 1$, for which $D_{1}(R)=$ $306 e^{-e^{-0.008(R-120)}}$. The flood damage function curve in 2005 is taken as economic development curve $\mathrm{S} 2$, for which $D_{2}(R)=$ $448 e^{-e^{-0.008(R-120)}}$. The maximum flood damage $A$ increases from 306 to 448 million CNY. The impact of economic development can be computed by finding the difference between the S2 and S1 integral areas, which is shown as the shaded area in Figure 9. Due to urbanization and economic development, the flood risk increases by $46.6 \%$ from 1999 to 2005 in the Taihu Basin, and it will increase by $59.8 \%$ from 2030 to 2050. The impact of increased economic development on flood risk will increase in the future.

Flood control capability development curve S3 is given by $D_{3}(R)=448 e^{-e^{-0.0088(R-240)}}$. It is assumed that the flood control standard has improved. The critical return period $R_{c}$ increases from 120 to 240 years. The benefits of flood control mechanisms can be expressed as the difference between the S2 and S3 integral areas, which is shown as the shaded area in Figure 10. If the flood control standard increases by a factor of two, the flood risk will decrease by $14.54 \%$.

Flood vulnerability change curve $S 4$ is given by $D_{4}(R)=$ $448 e^{-e^{-0.0176(R-240)}}$. The integrated loss coefficient $k$ increases from 0.009 to 0.018 . The intersection point of S3 and S4 is $\left(R_{i}, D_{i}\right)$. When $0<R<R_{i}$, the flood damage decreases. When $R>R_{i}$, the flood damage increases. With changes in 


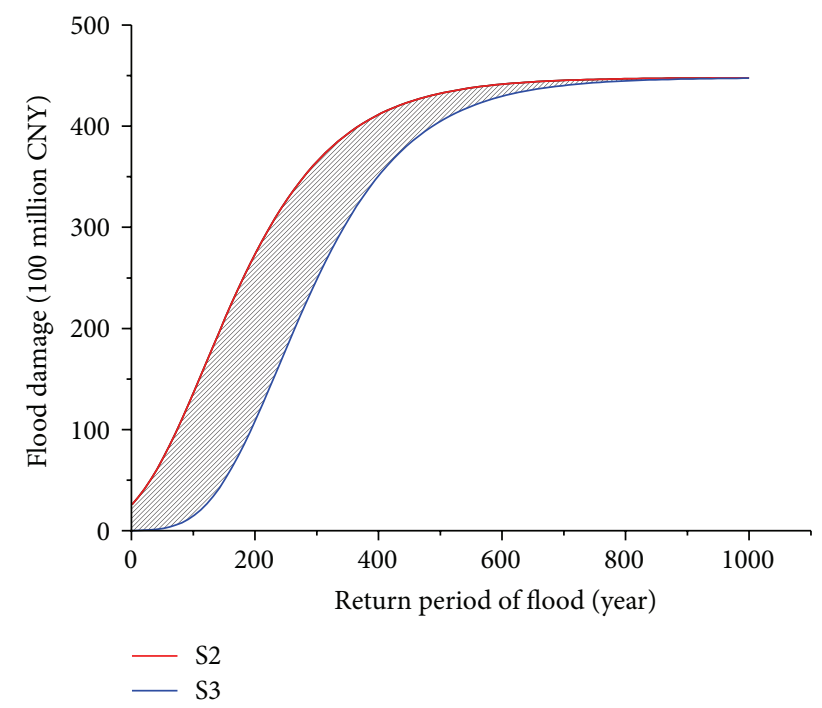

FIGURE 10: The impact of flood control capability development.

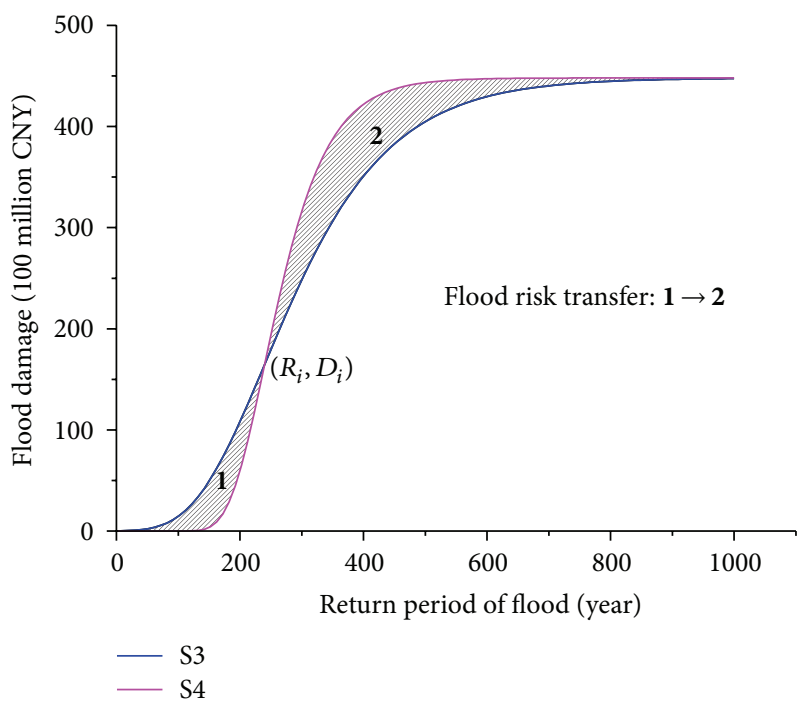

FIGURE 11: The impact of flood vulnerability change.

flood vulnerability, the flood risk shifts from shaded area $\mathbf{1}$ to shaded area 2, which is shown in Figure 11:

$$
\begin{gathered}
I_{\text {decrease }}=\frac{\int_{0}^{R_{i}} D_{3}(R)-D_{4}(R) d R}{\int_{0}^{R_{i}} D_{3}(R) d R}=48.1 \%, \\
I_{\text {increase }}=\frac{\int_{R_{i}}^{1000} D_{4}(R)-D_{3}(R) d R}{\int_{R_{i}}^{1000} D_{3}(R) d R}=6.7 \% .
\end{gathered}
$$

3.3.2. The Index of Urban Flood Control Management. As shown in Figure 12, $D_{2}(R)$ is the function curve of 2005. $D_{2}^{\prime}(R)$ and $D_{2}^{(2)}(R)$ are the first and second derivative curves of the flood $R-D$ function, respectively, and the parameters are $R_{\mathrm{A}}=10$ years, $R_{\mathrm{C}}=120$ years, and $R_{\mathrm{B}}=230$ years. Point $\mathrm{A}$ is the damage-arising point, point $\mathrm{B}$ is the damage-ceasing

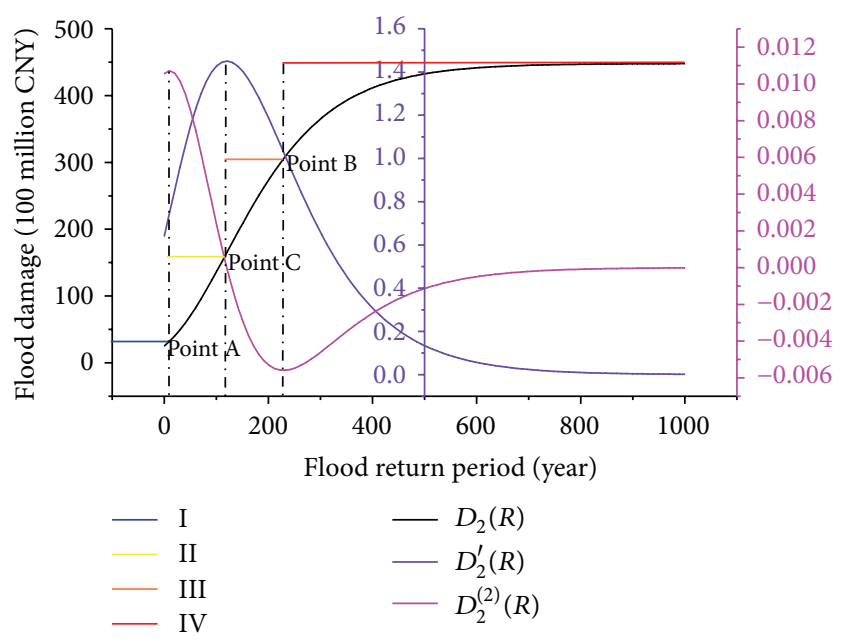

FIgURE 12: The turning points and derivative curves of the $R-D$ function (2005). Labels "I, II, III, and IV" represent four grades of flood damage: small, medium, large, and larger, respectively. They correspond with Figure 4 and Table 6.

point, and point $\mathrm{C}$ is the damage transition point. These three points divide the $D_{2}(R)$ curve into four parts that can be used to determine standard grades of flood disaster damage. The four grades are I small, II medium, III large, and IV larger. Flood grade division can be utilized to develop flood control standards and flood control planning.

Damage transition point $\mathrm{C}$ corresponds to parameter $R_{c}$ (critical return period), which is associated with the integrated flood defense capability or flood control standard of the basin. Resistance is related to the system's ability to prevent floods, while resilience determines the ease with which the system recovers from floods [35]. Thus, the demarcation line of these two processes is the integrated standard of flood control mechanisms or flood defense capability. Within the defense standard, the flood control mechanisms operate well. Resistance strategies are aimed at flood prevention. When the flood scale exceeds the defense capability, the situation becomes out of control. The resilience strategy aims to minimize the flood impacts and enhance the recovery from those impacts. Different strategies are designed for different grades of flood hazards (Table 6).

\section{Conclusion}

China is in a stage of rapid urbanization and has huge potential for economic growth. Because the pressure associated with flood risk caused by urbanization is still increasing, flood risk management must be reconsidered. The S-shaped function of the flood return period and damage can describe the impacts of socioeconomic development, urbanization degree, and flood control capability improvements very well. The main advantage of this model is that its application is not restricted by the scale of the study area. It can be utilized for flood damage assessment and prediction. Three conclusions can be drawn from this research.

(1) Due to urbanization and economic development, the flood risk increased by $46.6 \%$ from 1999 to 2005 in the Taihu 
TABLE 6: The grades of flood hazards and main strategies.

\begin{tabular}{|c|c|c|c|c|c|}
\hline Grade & Return period & Flood damage & Turning point & Physical meaning & Main strategy \\
\hline $\mathrm{I}$ & $0<R \leqslant R_{\mathrm{A}}$ & Small & Point A & Damage-arising point & \multirow{3}{*}{ Resistance strategy } \\
\hline \multirow{2}{*}{ II } & \multirow{2}{*}{$R_{\mathrm{A}}<R \leqslant R_{\mathrm{C}}$} & \multirow{2}{*}{ Medium } & Point A & Damage-arising point & \\
\hline & & & Point C & Damage transition point & \\
\hline \multirow{2}{*}{ III } & \multirow{2}{*}{$R_{\mathrm{A}}<R \leqslant R_{\mathrm{B}}$} & \multirow{2}{*}{ Large } & Point C & Damage transition point & \multirow{3}{*}{ Resilience strategy } \\
\hline & & & Point B & Damage-ceasing point & \\
\hline $\mathrm{V}$ & $R \geqslant R_{\mathrm{B}}$ & Larger & Point B & Damage-ceasing point & \\
\hline
\end{tabular}

Basin, and it will increase by $59.8 \%$ from 2030 to 2050 . The impact of increased economic development on flood risk will increase in the future. When the flood control standard increased by a factor of two in 2005, the flood risk decreased by $14.54 \%$. It is difficult to meet the increasing demand for flood control solely using structural measures. If the flood vulnerability changes, the flood risk will not increase but will transfer. A flood vulnerability method should be provided to effectively decrease the flood risk in future studies.

(2) The turning points of $R-D$ functions provide an important basis for flood risk management. The critical return period $R_{c}$ is 120 years in the Taihu Basin. It describes the composite flood control standard. This paper discusses the damage transition point as the boundary between the resistance strategy and resilience strategy in flood risk management systems.

(3) The model accuracy can be improved by verifying more data. Considering the limitations of historical flood data, only the 1999 Taihu Basin flood was used to verify the simulation models. The relationship between the maximum flood damage $A$ and socioeconomic development has been proven. In the future, the relationships between other parameters and meaningful statistical data should be verified. In addition, accurate simulations of flood control mechanisms should be provided using hydraulic models, and reasonable assessment indexes of flood control capability and flood vulnerability should be created. The rationality of parameters $R_{c}$ and $k$ will be verified in further studies.

\section{Competing Interests}

The authors declare that there is no conflict of interests regarding the publication of this paper.

\section{Acknowledgments}

The work described in this paper was supported by the following: (1) Key Projects in the National Science \& Technology Pillar Program during the Twelfth Five-Year Plan Period (no. 2012BAC21B02) and (2) Public Welfare Special Research Projects of Ministry of Water Resources (nos. 201401038 and 201501014).

\section{References}

[1] X.-T. Cheng, "Strategic demand for enhancing flood and drought management and investigation on policies of water governance," Journal of Hydraulic Engineering, vol. 39, no. 10, pp. 1197-1203, 2008 (Chinese).

[2] H. Wang, C.-Z. Li, and X.-T. Cheng, "Quantitative analysis of storm water management strategies in the process of watershed urbanization," Journal of Hydraulic Engineering, vol. 46, no. 3, pp. 271-279, 2015 (Chinese).

[3] X.-T. Cheng and C.-C. Li, "The evolutionary trend, key features and countermeasures of urban flood risk," China Flood \& Drought Management, vol. 25, no. 3, pp. 6-9, 2015 (Chinese).

[4] C. P. Konrad, "Effects of urban development on floods," U.S. Geological Survey Fact Sheet 076-03, 2003, http://pubs.usgs.gov/fs/fs07603/.

[5] S. Das and R. Lee, "Nontraditional methodology for flood stagedamage calculations," Journal of the American Water Resources Association, vol. 24, no. 6, pp. 1263-1272, 1988.

[6] E. C. Penning-Rowsell and J. B. Chatterton, "The benefits of flood alleviation: a manual of assessment techniques," Geographical Journal, vol. 145, no. 3, pp. 951-952, 1977.

[7] D. J. Parker, C. H. Green, and P. M. Thompson, Urban Flood Protection Benefits: A Project Appraisal Guide, Gower Technical Press, England, UK, 1987.

[8] C. Scawthorn, N. Blais, H. Seligson et al., "HAZUS-MH flood loss estimation methodology. I: overview and flood hazard characterization," Natural Hazards Review, vol. 7, no. 2, pp. 60 71, 2006.

[9] C. Scawthorn, P. Flores, N. Blais et al., "HAZUS-MH flood loss estimation methodology. II. Damage and loss assessment," Natural Hazards Review, vol. 7, no. 2, pp. 72-81, 2006.

[10] M. Hürlimann, D. Rickenmann, V. Medina, and A. Bateman, "Evaluation of approaches to calculate debris-flow parameters for hazard assessment," Engineering Geology, vol. 102, no. 3-4, pp. 152-163, 2008.

[11] H.-Y. Liao, T.-H. Chang, A.-P. Wang, and B.-W. Cheng, "Fuzzy comprehensive assessment of typhoon flood," WSEAS Transactions on Environment and Development, vol. 4, no. 3, pp. 257266, 2008.

[12] Y. Chen, H. Zhou, H. Zhang, G. Du, and J. Zhou, "Urban flood risk warning under rapid urbanization," Environmental Research, vol. 139, no. 5, pp. 3-10, 2015.

[13] J.-W. Lin, C.-W. Chen, and C.-Y. Peng, "Potential hazard analysis and risk assessment of debris flow by fuzzy modeling," Natural Hazards, vol. 64, no. 1, pp. 273-282, 2012.

[14] M. Karamouz and S. Nazif, "Reliability-based flood management in urban watersheds considering climate change impacts," Journal of Water Resources Planning and Management, vol. 139, no. 5, pp. 520-533, 2013.

[15] J. Yazdi and S. A. A. S. Neyshabouri, "A simulation-based optimization model for flood management on a watershed scale," Water Resources Management, vol. 26, no. 15, pp. 45694586, 2012. 
[16] L. Song, S. Zhao, W. Liao, and Z. Wang, "Neural network application based on GIS and Matlab to evaluation of flood risk," in Proceedings of the International Conference on Remote Sensing, Environment and Transportation Engineering (RSETE '13), pp. 296-299, Nanjing, China, July 2013.

[17] Z.-X. Ding, J.-R. Li, and L. Li, "Method for flood submergence analysis based on GIS grid model," Journal of Hydraulic Engineering, no. 6, pp. 56-60, 2004 (Chinese).

[18] H. Qi, P. Qi, and M. S. Altinakar, "GIS-based spatial Monte Carlo analysis for integrated flood management with two dimensional flood simulation," Water Resources Management, vol. 27, no. 10, pp. 3631-3645, 2013.

[19] J. X. Li and S. L. Su, "Calculation model of water pollution induced economic loss for river basin," Journal of Hydraulic Engineering, vol. 34, no. 10, pp. 68-74, 2003 (Chinese).

[20] J. R. Li, Z. X. Ding, S. F. Huang, and Y. L. Hu, "Research of flood and waterlogging loss assessment model based on spatial distribution social-economic database," Journal of China Institute of Water Resources and Hydropower Research, vol. 1, no. 2, pp. 104-110, 2003 (Chinese).

[21] J. J. Yu, X. S. Qin, and O. Larsen, "Joint Monte Carlo and possibilistic simulation for flood damage assessment," Stochastic Environmental Research and Risk Assessment, vol. 27, no. 3, pp. 725-735, 2013.

[22] M. Chen, F. Zhou, J. Ma, G. Chen, H. Ni, and Y. Hu, "Waterinduced disaster damage function and flood and water-logging damage assessment," Journal of Hydraulic Engineering, vol. 46, no. 8, pp. 883-891, 2015.

[23] P. P. Pan, G.-S. Yang, W.-Z. Su, and X.-X. Wang, "Impact of land use change on cultivated land productivity in Taihu Lake Basin," Scientia Geographica Sinica, vol. 35, no. 8, pp. 990-998, 2015 (Chinese).

[24] X. Jiabi, P. Sayers, S. Dongya, and Z. Hanghui, "Broad-scale reliability analysis of the flood defence infrastructure within the Taihu Basin, China," Journal of Flood Risk Management, vol. 6, no. 1, pp. 42-56, 2013.

[25] X. B. Xu and G. S. Yang, "Spatial and temporal changes of multiple cropping index in 1995-2010 in Taihu Lake Basin, China," Transactions of the Chinese Society of Agricultural Engineering, vol. 29, no. 3, pp. 148-155, 2013 (Chinese).

[26] X. T. Cheng, E. P. Evans, H. Y. Wu et al., "A framework for longterm scenario analysis in the Taihu Basin, China," Journal of Flood Risk Management, vol. 6, no. 1, pp. 3-13, 2013.

[27] L. Liu, Z. X. Xu, N. S. Reynard, C. W. Hu, and R. G. Jones, "Hydrological analysis for water level projections in Taihu Lake, China," Journal of Flood Risk Management, vol. 6, no. 1, pp. 1422, 2013.

[28] J. M. Wicks, C. Hu, M. Scott, L. Chen, and X. Cheng, "A broad scale model for flood simulation in the Taihu Basin, China," Journal of Flood Risk Management, vol. 6, no. 1, pp. 33-41, 2013.

[29] E. C. Penning-Rowsell, W. Yanyan, A. R. Watkinson, J. Jiang, and C. Thorne, "Socioeconomic scenarios and flood damage assessment methodologies for the Taihu Basin, China," Journal of Flood Risk Management, vol. 6, no. 1, pp. 23-32, 2013.

[30] C. Q. Yu, J. W. Hall, X. T. Cheng, and E. P. Evans, "Broad scale quantified flood risk analysis in the Taihu Basin, China," Journal of Flood Risk Management, vol. 6, no. 1, pp. 57-68, 2013.

[31] J. W. Hall, R. J. Dawson, P. B. Sayers, C. Rosu, J. B. Chatterton, and R. Deakin, "A methodology for national-scale flood risk assessment," Proceedings of the Institution of Civil Engineers: Water \& Maritime Engineering, vol. 156, no. 3, pp. 235-247, 2003.
[32] O. Hoes and W. Schuurmans, "Flood standards or risk analyses for polder management in the Netherlands," Irrigation \& Drainage, vol. 55, supplement 1, pp. S113-S119, 2006.

[33] J. Hall and D. Solomatine, "A framework for uncertainty analysis in flood risk management decisions," International Journal of River Basin Management, vol. 6, no. 2, pp. 85-98, 2008.

[34] Y.-L. Ou and H.-Y. Wu, The Taihu Lake Basin Flood in 1999, China Water Power Press, Beijing, China, 2001 (Chinese).

[35] K. M. De Bruijn, "Resilience and flood risk management," Water Policy, vol. 6, no. 1, pp. 53-66, 2004. 

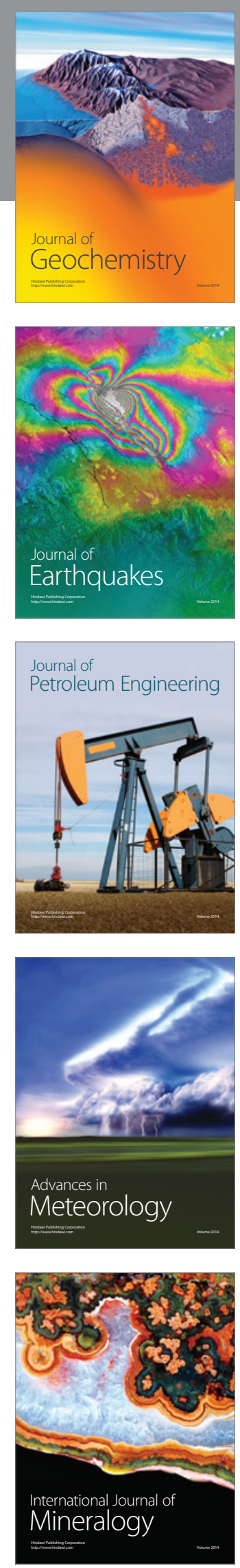
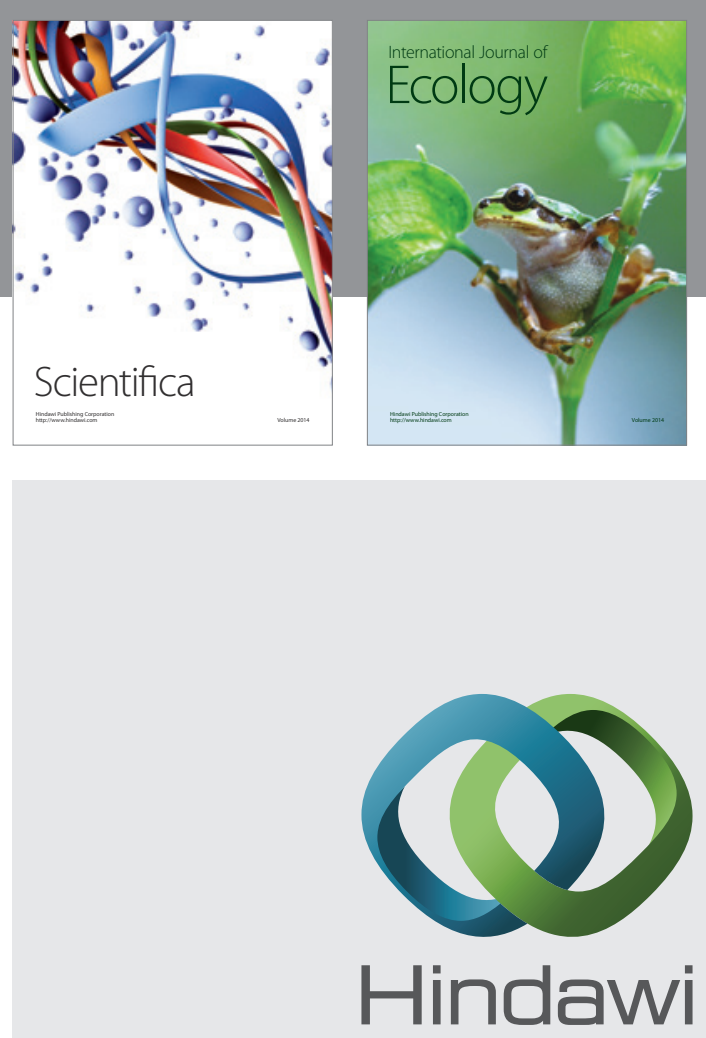

Submit your manuscripts at

http://www.hindawi.com
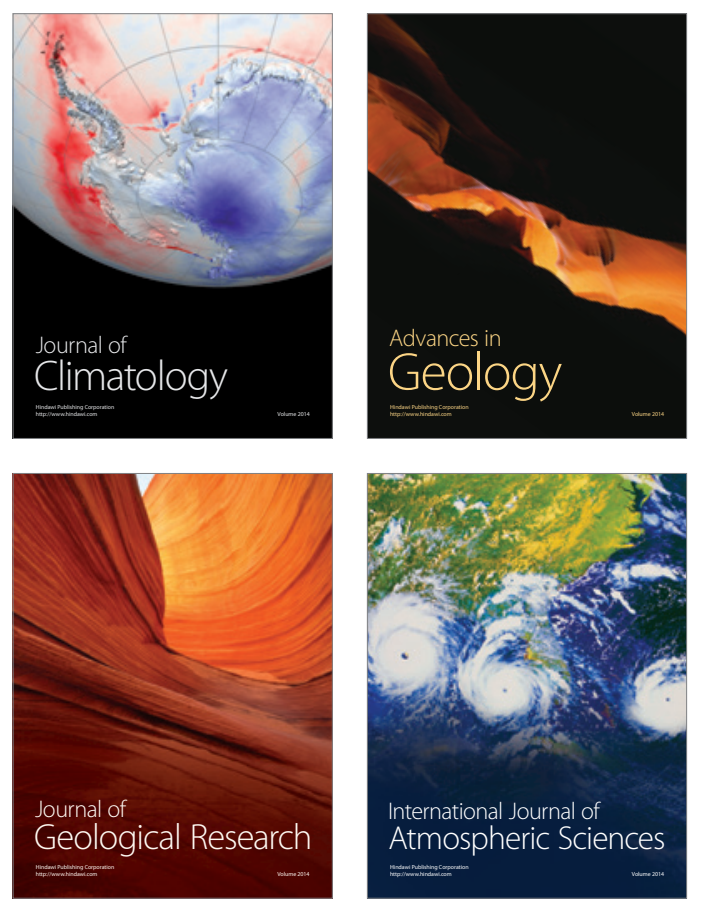

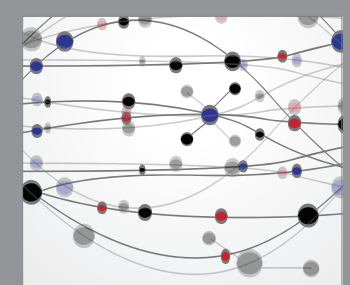

The Scientific

\section{World Journal}
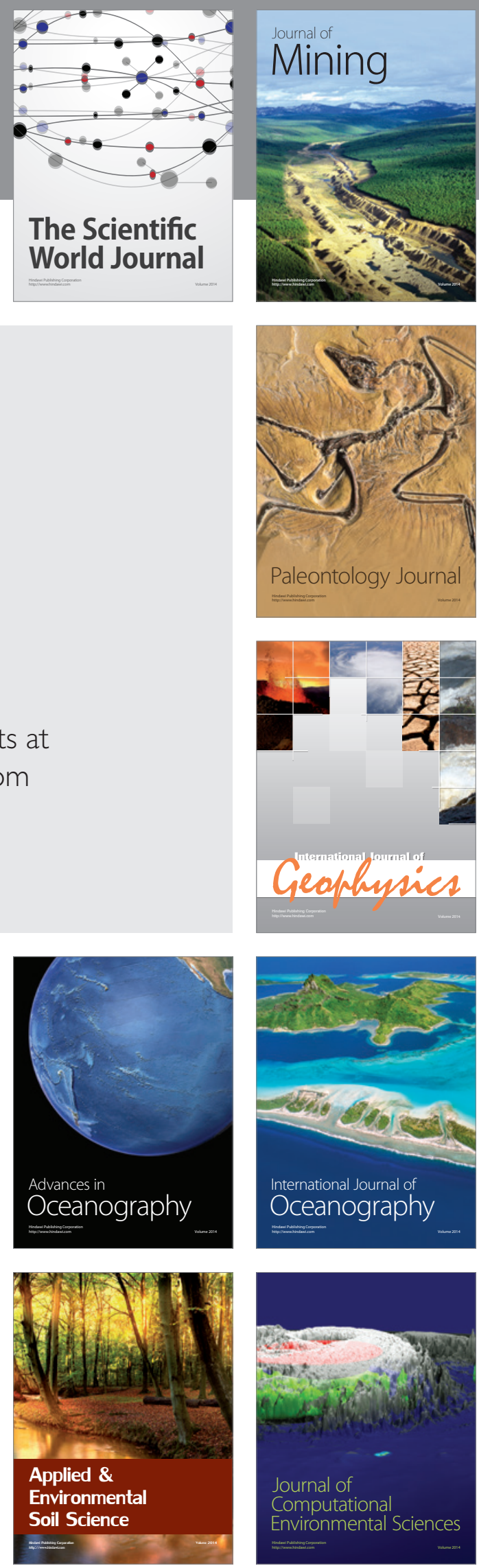